Mens

revue d'histoire intellectuelle de l'Amérique française

\title{
Allan Smith. Le Canada : une nation américaine? Réflexions sur le continentalisme, l'identité et la mentalité canadienne. Québec, Presses de l'Université Laval, 2005. 379 p. Traduction de l'anglais par Sophie Coupal.
}

\section{Louis Balthazar}

Volume 8, numéro 2, printemps 2008

URI : https://id.erudit.org/iderudit/1022844ar

DOI : https://doi.org/10.7202/1022844ar

Aller au sommaire du numéro

Éditeur(s)

Centre de recherche en civilisation canadienne-française

ISSN

1492-8647 (imprimé)

1927-9299 (numérique)

Découvrir la revue

Citer ce compte rendu

Balthazar, L. (2008). Compte rendu de [Allan Smith. Le Canada : une nation américaine ? Réflexions sur le continentalisme, l'identité et la mentalité canadienne. Québec, Presses de l'Université Laval, 2005. 379 p. Traduction de l'anglais par Sophie Coupal.] Mens, 8(2), 427-432.

https://doi.org/10.7202/1022844ar d'utilisation que vous pouvez consulter en ligne. 
qui suscite la curiosité mais l'avant et l'après-Asbestos qui représentent le principal intérêt de l'ouvrage. Le virage conservateur de l'Église et de certaines élites y est ici brillement expliqué. De plus, Clavette explore le fonctionnement des associations patronales, facette qui mériterait davantage d'attention de la communauté historienne. Bref, nous avons affaire ici à un ouvrage fort utile qui ouvre d'intéressantes perspectives en histoire des idées.

Jonathan Fournier Département d'histoire Université de Sherbrooke

\begin{abstract}
Allan Smith. Le Canada : une nation américaine? Réflexions sur le continentalisme, l'identité et la mentalité canadienne. Québec, Presses de l'Université Laval, 2005. 379 p. Traduction de l'anglais par Sophie Coupal.
\end{abstract}

Cet ouvrage est la traduction d'un ensemble de textes écrits entre 1970 et 1992, réunis en un volume publié en 1994. Un article plus récent (2000) a été ajouté à l'ouvrage originel dont on a soustrait trois textes (et non pas deux comme l'écrit Jean-François Côté, le directeur de la collection, dans la préface) portant sur l'Ontario, la Colombie-Britannique et les provinces de l'Ouest. L'article plus récent constitue le chapitre 5 (et non le $6^{\mathrm{e}}$, autre erreur de la préface).

Ces écrits demeurent remarquablement pertinents en cette première décennie du vingt-et-unième siècle, ce qui témoigne de la finesse et de la lucidité de l'analyse complexe à laquelle s'est livré cet excellent historien. Le lecteur francophone, souvent peu au fait des paramètres de l'identité cana- 
dienne, tels que conçus par les intellectuels anglo-canadiens, $\mathrm{y}$ trouvera matière à réflexion sur la genèse et l'histoire du Canada moderne.

L'approche de Smith apparait particulièrement réaliste et fertile. Empruntant l'expression de "nation américaine » au titre d'un ouvrage du célèbre écrivain-journaliste de Winnipeg, John W. Dafoe (1935), il entend placer toute recherche sur l'identité canadienne dans le cadre continental. Selon cette approche, on ne comprendra rien sur le Canada si on ne le situe pas dans un rapport existentiel avec son voisin, les ÉtatsUnis d'Amérique. Cette façon de voir se vérifie pleinement si l'on prend conscience du fait inéluctable que le Canada moderne est d'abord et avant tout un sous-produit de la révolution américaine. Certes, le Canada anglophone est né d'une volonté de fidélité à l'Empire britannique, mais cette volonté a été façonnée par les circonstances du mouvement indépendantiste américain. En d'autres termes, la grande majorité des premiers habitants anglophones du Canada est issue des colonies britanniques rebelles. Même les Canadiens (français) ont été reconnus comme formant une société distincte dans le cadre britannique en raison de l'appréhension du mouvement révolutionnaire au sud. Leur destinée a été marquée par leur refus de se joindre à la révolution américaine. Par la suite, toute l'évolution du Canada s'inscrit dans la mouvance du voisinage américain, y compris la Confédération de 1867.

Cette évolution peut être caractérisée comme un lent et graduel mouvement de dissociation de la métropole britannique, un peu comme si les Canadiens avaient décidé de refaire la sécession d'avec la Grande-Bretagne d'une manière lente et graduelle, sans jamais trop le souligner, à l'opposé de la manière brutale et décisive de la déclaration d'indépendance des États-Unis. À l'égard du Canada, le voisin du sud a assumé « au vingtième siècle le rôle que la Grande-Bretagne 
avait joué au dix-neuvième. [...] Par conséquent, la part du caractère anglo-canadien qui reposait sur une participation à la culture et à la civilisation britanniques [...] fut remplacée, non par une définition précise et acceptable pour tous de la canadianité, mais par l'idée du Canada comme nation américaine. » (p. 208) Il n'en résulte pas pour autant une fusion avec les États-Unis. Tout en prenant résolument place dans le Nouveau Monde, le Canada n'en conserve pas moins une identité propre qui tient au fait qu'il se refuse pendant longtemps à se considérer comme une nation homogène. Il se définit très tôt, bien avant la loi de 1971 sur le multiculturalisme, comme essentiellement pluraliste, comme une "mosaïque». En somme, « le nationalisme canadien tranche clairement avec son équivalent américain. C'est en fait un non-nationalisme, de la même façon que le Canada est une non-nation. » (p. 222)

Ces propos se retrouvent au chapitre 6, «Métaphores et nationalités en Amérique du Nord». Selon l'auteur, c'est en raison de ce pluralisme non-national que George-Étienne Cartier s'est engagé à défendre la Confédération canadienne et la création d'une nouvelle nationalité qui pouvait englober une nation proprement canadienne-française, de la même façon que l'Empire britannique laissait place à une grande diversité de races et de nations. Smith reconnait toutefois que l'intransigeance de la majorité anglo-canadienne finit par effacer, dans l'esprit des nationalistes canadiens-français, toute la confiance qu'ils avaient pu accorder au soi-disant caractère pluraliste du pays. L'auteur relève des paroles fort révélatrices d'Armand Lavergne qui déclarait, dès 1907 : «En constituant le Canadien-français, qui habite le pays depuis sa découverte, l'égal en droits et en privilèges du Doukhobor ou du Galicien qui viennent de débarquer, nous avons ouvert entre l'Est et l'Ouest canadiens un gouffre que rien ne saura 
combler. » (p. 213) Cent ans plus tard, que dire de plus? Smith en conclut que "le chantre d'un Canada bilingue et multiculturel céda la place au partisan d'un Canada bilingue et biculturel. Les mutations du Canada anglais avaient métamorphosé Cartier en Bourassa. » (p. 215) Déjà au début du vingtième siècle apparaissaient donc les failles de la politique du multiculturalisme.

C'est en 1970 que Smith rédigeait ce texte éclairant, peut-être le meilleur de tout l'ouvrage. Il pouvait toujours écrire à cette époque que Pierre Trudeau était en train de mettre en œuvre sa volonté de dissocier l'État de la nation (p. 216). Nous savons maintenant que le mandat de ce premier ministre a été marqué au contraire par la création d'un État-nation canadien alimenté par un nationalisme qui ressemble de plus en plus au nationalisme américain. Depuis 1995, surtout, les disciples de Trudeau se sont employés à faire accréditer la notion d'une grande nation canadienne une et indivisible, à l'image de la république voisine. À l'instar des Américains, les élites canadiennes ont souvent recours aux superlatifs pour caractériser leur pays.

D'autres chapitres de ce livre méritent aussi qu'on s'y attarde, notamment le chapitre 4, "La culture canadienne, le rôle de l'État et la gestion du nouveau continentalisme », dans lequel l'auteur trace une grande fresque historique des efforts du Canada (anglophone surtout) pour se dissocier de la culture américaine, pour combattre l'influence constante et croissante à travers les années, de la culture de masse des ÉtatsUnis. Dès le début du vingtième siècle, des élites anglo-canadiennes appellent de leurs vœux une intervention du gouvernement fédéral pour encourager l'essor de la création artistique. Smith s'empresse de noter que les Québécois ne voyaient pas les choses du même œil. Le gouvernement canadien n'en vint pas moins à mettre sur pied tout un arsenal d'institutions devant promouvoir la production culturelle partout au pays. 
Le chapitre 5, «Un continent d'idées : conceptions de la relation canado-américaine au vingtième siècle ", constitue un tour d'horizon des relations de plus en plus étroites entre les deux pays, à tous les niveaux. Ces relations culminent avec l'accord de libre-échange de 1989 et la conception d'un « amalgame continental unique ", d'une grande région sans frontière. à toutes fins utiles. Selon plusieurs analystes de la relation canado-américaine, il existe un nombre croissant de dossiers et de questions qui se doivent d'être traités à l'échelle nordaméricaine dans un grand système où les transactions fonctionnent comme si elles avaient lieu à l'intérieur d'un seul pays. Allan Smith doit cependant noter en conclusion que le nationalisme, tout particulièrement du côté canadien, n'a pas dit son dernier mot. Les politiques et attitudes qui ont suivi les événements du 11 septembre 2001 et les réactions canadiennes à la politique de l'administration de George W. Bush lui ont donné raison. Il faut cependant compter avec la persistance de "l'idée canado-américaine ».

Bien que cet ouvrage soit traversé par une approche unique qui inspire chaque chapitre, il n'en demeure pas moins un conglomérat de textes écrits à des moments divers et en fonction de conjonctures particulières. Il n'en résulte pas une structure invitant une lecture continue. Le lecteur pourra davantage tirer profit de la lecture de l'un ou l'autre des chapitres. À cet égard, il est dommage que cette version française ne comporte pas, à l'instar de l'original, un index qui en aurait facilité la consultation.

Il n'était pas facile de rendre en français ces analyses subtiles et complexes. L'écriture d'Allan Smith n'appelle pas une traduction aisée. Dans l'ensemble, la traductrice s'en est bien tirée. Ici ou là cependant apparaissent des formulations plus ou moins heureuses. Voici, par exemple, une phrase qui écorche la syntaxe française: "Aurait-on pu trouver une 
meilleure façon d'y parvenir qu'en leur montrant que le meilleur de leur société provenait de, s'incarnait dans et encourageait l'effort individuel ? » (p. 320)

Il n'était pas possible, dans cet espace restreint, de rendre justice à un ouvrage aussi riche et stimulant sur plusieurs questions appartenant à cette inlassable quête d'une identité canadienne dans le cadre américain. Tous ceux qui cherchent à mieux comprendre le Canada et même le Québec ont intérêt à lire cet ouvrage.

Louis Balthazar

Département de science politique

Université Laval

\section{Jocelyn Létourneau. Que veulent vraiment les Québécois? Montréal, Boréal, 2006. 180 p.}

Constatant qu'« il est assurément difficile, voire périlleux, de qualifier la communauté nationale québécoise ", que « [j] usqu'ici la natiologie québécoise [...] n'a pas produit de résultat probant » (p. 126) et considérant que s'en ressentent le travail des historiens comme la praxis des contemporains, Jocelyn Létourneau réinvestit le champ métahistorique pour proposer « une problématique générale portant sur [...] l'intention nationale qui traverse l'histoire du Québec » (p. 8). L'auteur entend présenter « des points de vue inusités sur des lieux connus » (p. 9). Le texte est dense, suggestif et ambitieux, d'une hybridité, d'une facture et d'une orientation substantielle qui, selon toute vraisemblance, dérouteront et inspireront.

Bien qu'il s'agisse ici d'intentions, l'auteur opérationnalise d'emblée son paradigme en l'appliquant à quelques jalons cru- 